\title{
Contributions of Community Health Fund to Social Health Security in Kalambo District Rukwa, Tanzania
}

\author{
Alexander D. Kasonso (Corresponding author) \\ Department of Development Studies, College of Social Sciences and Humanities, \\ Sokoine University of Agriculture, P.O. Box 3024, Morogoro, Tanzania
}

Emanuel E. Chingonikaya

Department of Development Studies, College of Social Sciences and Humanities, Sokoine University of Agriculture, P.O. Box 3024, Morogoro, Tanzania

Anna N. Sikira

Department of Development Studies, College of Social Sciences and Humanities Sokoine University of Agriculture, P.O. Box 3024, Morogoro, Tanzania

Received: Aug. 5, 2020 Accepted: Sept. 14, 2020 Online published: Sept. 26, 2020

doi:10.5296/jpag.v10i3.17745 URL: https://doi.org/10.5296/jpag.v10i3.17745

\begin{abstract}
Community Health Fund (CHF) was established in 1996 as a District Council based pre-payment health insurance scheme in Tanzania with the aim of improving health of communities working in the informal sectors. However, since its formulation, it has been performing unsatisfactorily, and hence majority of Households (HHs) are not members while other members are withdrawing from the scheme. This necessitated the need for assessing the contribution of $\mathrm{CHF}$ on social health security among members. Specifically, this paper examined the challenges faced by households regarding CHF membership and analysed the contributions of $\mathrm{CHF}$ on its member. The study area was Kalambo District Council. A cross-sectional research design was used, whereas a simple random sampling technique through lottery method was employed to select the sample size of 354 respondents. Qualitative data were collected using Focus Group Discussions (FGDs) and Key Informant Interviews (KIIs), while quantitative data were collected using a questionnaire. Quantitative data were coded and analysed using IBM-SPSS. Qualitative data were analysed through content analysis. The results show that CHF contributed to social health security among its
\end{abstract}


members in the study area, through provision of health services to its members once they fall sick. On other hand, CHF had few members as only $24.3 \%$ of HHs had membership to CHF. One of the barriers for CHF was lack of awareness among communities about the existence of CHF, while other cited lack of money for contributing to CHF. Thus, the study concludes that CHF has not contributed significantly to the health security among targeted members. The study recommends that, CHF officials should widely sensitize communities through seminars and meetings about $\mathrm{CHF}$ and its benefits to them. Furthermore, CHF stakeholders should coordinate communities in the area to establish financial institutions such as Village Community Banks (VICOBA) where they can save and borrow money for registration cards.

Keywords: community health fund, contribution, social health security, Kalambo District

\section{Introduction}

Community Health Fund (CHF) is a District Council based pre-payment health insurance scheme in Tanzania (Kivelege, 2015). CHF is a health security service used to improve members' access to health care and strengthening health systems that provide a strong defence against emerging threats, which can be natural or man-made (WHO, 2007). Different countries use different mechanisms to promote health security systems (Martin, 2017). Europe has the highest level of social security expenditure at nearly $25 \%$ of the GDP, this has led to relatively high life expectancies to their people as compared to the life expectancy of the people in the rest of the world. This is followed by North America at 16.6 percent. Africa has the lowest level at 4.3 percent of the GDP (ILO, 2018).

In Sub Saharan African (SSA), approximately, 30 percent of the households are financing their health care by borrowing or selling their assets (Carapinha et al., 2010). This can probably cause difficulties to households (HHs) joining health insurance schemes. Exclusively, most of the SSA countries have undertaken different measures such as general government expenditure, private health expenditure, social security funds, private health insurance, and direct payment out of pocket in order to improve health status of their communities. Despite these measures, health of the vast majority of people in SSA remains in jeopardy (Carapinha et al., 2010). In contrast, South Africa has improved social security by covering 85 percent of the pensionable people and this has reduced poverty gap for pensioners by 94 percent (ILO, 2018). On the other hand, Rwanda has been doing well in the Community Health Insurance (CHI) scheme since it was introduced in 1999 (WHO, 2003). One of the reasons for good performance is the community awareness on community health insurance schemes.

Previously, the government of Tanzania was a major provider of health services from independence under the socialist ideology up to 1990s (URT, 2008). In the early 2000s, both private and public insurance schemes started to operate in the country (URT, 2008). The general objective of these schemes has been to fill the coverage gap of the universal health care financial support (Mubyazi, 2004). The categories of health insurance schemes that operate in Tanzania included Social Health Insurance (SHI) that covers public sector workers, Community Based Health Insurance (CBHI), and Private Health Insurance (PHI). National Health Insurance Fund (NHIF) is the only SHI in Tanzania. The CBHI schemes include 
Community Health Fund (CHF), Small Business Holdings Societies commonly known as "Vikundi vya Biashara Ndogondogo" (VIBINDO) and Mutual Health Scheme or "Umoja wa Matibabu Sekta Isiyo rasmi Dar es salaam" (UMASIDA), and the PHIs, which is African Air Rescue company (AAR) (Temba and Leonard, 2013). Despite the existence of social insurance schemes in Tanzania as mentioned above, majority of Tanzanians seem to be lacking health security. This is because membership fee is very high and commensurate to the earnings of most Tanzanians specifically workers in the informal sector (Ware, 2013).

Community Health Fund (CHF) was introduced in 1996, and piloted in Tabora Region, specifically in Igunga District, and later it was extended to other districts (Macha et al., 2015). In Kalambo District Council, the CHF was introduced in 2012 after the formulation of Kalambo District Council that was formally part of Sumbawanga District Council. Since the formulation of the $\mathrm{CHF}$, its coverage has still been low as it has remained with very few members over the time with enrolment far below the Health Sector Strategic Plan (HSSP) III target which was 45 percent of the population in prepayment schemes to be covered from 2008 to 2015 (Marwa et al., 2013).

In order for a fund to operate effectively, there is a need for registering more members, having good management and good health facilities (HPSS, 2018). Studies such as Msuya et al. (2004), Mtei and Mulligan (2007) and Marwa et al. (2013) found that the enrolment trend was not only declining, but also membership base was getting narrower as some members were withdrawing from the schemes. Recommendations for improvement and strengthening of various health security funds like laboratory services and qualified medical doctors as given by previous studies did not yield any results as the number of members continued to decrease and few/no new members continued registering to the schemes (URT, 2003; URT, 2008; Marwa et al., 2013; WHO, 2015; Martin, 2017). The reasons for low communities' enrolment to CHF and withdrawing of some members are not empirically known. Thus, this study assesses the contributions of CHF as a social health security scheme among its members. Hence, this study was conducted to inform communities on the importance of CHF. The results from this study would be beneficial to Government officials specifically CHF implementers, health sectors, policy makers, CHF members and non-members, NGOs, academic staff and Donors, hence worth to be undertaken.

Theoretically, the study adopted Protection Motivation Theory (PMT) (Rogers, 1983). The theory describes adaptive and maladaptive coping with health threats as a result of two appraisal processes: A threat appraisal and a coping appraisal, where the behavioural options of mitigating the threat are evaluated. The appraisal of health threats and the appraisal of the coping responses result in the intention of performing adaptive or maladaptive responses. Maladaptive responses place an individual at a health risk. The households that are non-members of CHF are considered to be under the maladaptive category, which is much vulnerable to diseases risks compared to adaptive members who are CHF members in this context. The roles of the behavioural options of mitigating the threat are evaluated by government organs under the Ministry of Health, Gender, Community Development, Elderly and Children (MHGCDEC) and Local Government Authority. The outcome of the role of Government organs, specifically $\mathrm{CHF}$ is to ensure that health security to its citizen is 
enhanced.

Conceptually, the outcome variables like distance from HHs to health facilities, availability of medicine and qualified health services provider, show the contribution of CHF in Tanzanian beneficiaries. This has led to improved availability of medicines, laboratory services; qualified health services providers, reduced distance from home to the health facilities with cost effective health services. These outcomes resulted to better health security provision including assurance of better health services, accessibility to health care and affordability of health services among CHF beneficiaries.

Revealing the contribution of $\mathrm{CHF}$ to its members on social health security will influence other non-members to join the scheme. The questions that addressed in this paper include, what are the challenges faced by households in joining CHF? Are there contributions of CHF to its member's health security? Specifically, the paper examined the challenges faced by households concerning CHF membership and analysed the contributions of CHF to its members' health security. According to WHO (2003), people are attracted to health insurance with better health service provision, which results to good health security.

\section{Methodology}

The study was conducted in Kalambo District Council, which is one of the three districts of Rukwa Region in Tanzania. The district was chosen because majority of the people were employed in the informal sectors, which is the main target of CHF (URT, 2012). The main economic activities carried out by majority of the communities in the district include crop farming, livestock keeping, fishing, trading, and bee keeping. In addition, Kalambo District is one of the districts with few CHF members as it covers only 7.5 percent of the population based on HSSP III targets unlike in Singida and Mbeya where 54.4 and 43 percent of the population in the two regions are covered by CHF respectively (URT, 2015).

The study used a cross-sectional research design, (Baltazari et al., 2012, Creswell 2014).

Table 1. Number of sampled households in each study village

\begin{tabular}{llrrrr}
\hline Ward & Village & $\begin{array}{r}\text { Total } \\
\text { households (n) }\end{array}$ & $\begin{array}{r}\text { Sampled } \\
\text { households (n) }\end{array}$ & $\begin{array}{r}\text { CHF } \\
\text { members }\end{array}$ & $\begin{array}{r}\text { CHF } \\
\text { non-members }\end{array}$ \\
\hline Msanzi & Msanzi & 599 & $599 / 3060 * 354=69$ & 20 & 49 \\
& kati & & & & \\
Matai & Singiwe & 300 & $300 / 3060 * 354=35$ & 8 & 27 \\
Mkowe & Mbuza & 564 & $564 / 3060 * 354=65$ & 11 & 54 \\
Kisumba & Kasote & 500 & $500 / 3060 * 354=58$ & 14 & 44 \\
Kasanga & Kasanga & 1097 & $1097 / 3060 * 354$ & 33 & 94 \\
& & & $=127$ & & \\
Total & & $\mathbf{3 0 6 0}$ & $\mathbf{3 5 4}$ & $\mathbf{8 6}$ & $\mathbf{2 6 8}$ \\
\hline
\end{tabular}

The sample size of HHs was determined by using Yamane`s (1974) formula as cited by Israel (2013) which is: 
$n=\frac{N}{1+N(e)^{2}}=3060 / 1+3060(0.05)^{2}=354$. Where: $\mathrm{n}$ is the sample size, and $\mathrm{N}$ is the

population. In this study, $\mathrm{N}$ is the estimated number of households in five selected villages.

Since there were few CHF members while the great interest of the research was in them, simple stratified sampling was used to select equal numbers of CHF members and non-members (Hansen et al., 1953). The names of all household heads were obtained from village offices that showed CHF members and non-members. The sample size was divided equally basing on simple stratified sampling by the following formula in order to get number of households per each village:

$$
a=\frac{n}{N} \times b
$$

Where: $\mathrm{a}$, is sample size for each village, $\mathrm{n}$ is the total number of sampled households for 5 villages, $\mathrm{N}$ is the target households for the 5 villages and $\mathrm{b}$ is the target households in each village. A total sample size of $354 \mathrm{HHs}$ was obtained (Table 1). The sample size of 354 respondents from five wards was involved in the study. The number of CHF members was achieved from the dispensary of particular village hence the ration between number of households and CHF members was used to determine representative sample size of CHF members and non-members.

Both qualitative and quantitative data were collected. Quantitative data were collected through survey method using questionnaire. The data collected through this method included household (HHs) demographic characteristics and the contributions of CHF health security. Qualitative data were collected through Focus Group Discussions (FGDs) with 6-8 participants (Byers, 1996) who were purposively selected in order to ensure the participations of men and women as well as CHF members and non-members of CHF in the discussion. Two FGDs were conducted per each village in order to collect qualitative data to complement the data collected through the questionnaire survey. The information captured through FGDs includes CHFs challenges leading to poor health security, as well as strengths and weaknesses of the CHF. FGDs participants were those working in informal sectors, which are the targeted group of CHF. Moreover, Key Informant Interviews (KIIs) were conducted specifically with those who were working with CHF such as the District Commissioner (DC), the District Medical Officer (DMO), Clinical Officers (COs), Nurses, Ward Executive Officers (WEOs), Ward Community Development Officers and Village Executive Officers (VEOs). A checklist of questions was used during data collection from KIIs. Types of information collected through this method were based on achievements of the CHF and barriers against joining CHF for the majority of HHs together with strengths and weaknesses of the CHF.

Quantitative data were coded and analysed using IBM-SPSS while descriptive statistics such as frequencies and percentages were employed to describe socio-demographic information. Additionally, a multiple linear regression model was adapted for the contributions of the CHF 
to its members because its dependent variable was continuous. Linear regression model is described as follows:

$\mathrm{Y}_{\mathrm{i}}=\beta_{\mathrm{o}}+\beta_{1} \mathrm{X}_{1}+\beta_{2} \mathrm{X}_{2}+\beta_{3} \mathrm{X}_{3}+\beta_{4} \mathrm{X}_{4}+\beta_{5} \mathrm{X}_{5}+\beta_{6} \mathrm{X}_{6}+\mathrm{e}_{\mathrm{i}}$

Where;

$\mathrm{Y}_{\mathrm{i}}=$ Frequency of accessing health services for year $2018(1=$ once, $2=$ twice, $3=$ more than twice, $4=$ not concerned)

$\mathrm{X}_{1}=$ Community awareness on CHF existence $(0=$ No, $1=$ Yes $)$

$\mathrm{X}_{2}=$ CHF membership $(0=$ not member, $1=$ member $)$

$\mathrm{X}_{3} \quad=$ Training on CHF matters $(0=$ No, $1=$ Yes $)$

$\mathrm{X}_{4} \quad=$ CHF Supplies of medicine to its members $(0=$ No, $1=$ Yes $)$

$\mathrm{X}_{5} \quad=$ The lack of choices for health services to CHF members $(0=$ No, $1=$ Yes $)$

$\mathrm{X}_{6}=$ Accessibility of health services to CHF members $(0=$ No, $1=$ Yes $)$

$\beta_{0} \quad=$ Intercept

$\beta_{1-6} \quad=$ Parameters to be estimated

$\mathrm{e}_{\mathrm{i}} \quad=$ Random error term.

The health security in this paper was assessed through frequency of members visiting and accessing the health services in the year 2018. Qualitative data were analysed using content analysis approach, whereby recorded discussions were broken down into smallest meaningful units of information.

\section{Results and Discussion}

Table 2. Households' Socio-demographic Characteristics $(n=354)$

\begin{tabular}{|c|c|c|c|c|c|c|c|}
\hline \multirow[t]{2}{*}{ Variable } & & \multicolumn{2}{|c|}{ CHF Member } & \multicolumn{2}{|c|}{ CHF Non-Member } & \multicolumn{2}{|c|}{ Total } \\
\hline & & $\mathbf{n}$ & $\%$ & $\mathbf{n}$ & $\%$ & $\mathbf{n}$ & $\%$ \\
\hline \multicolumn{8}{|l|}{ Age } \\
\hline $35-59$ & & 55 & 21.1 & 206 & 78.9 & 261 & 73.7 \\
\hline 60-above & & 31 & 33.3 & 62 & 66.7 & 93 & 26.3 \\
\hline \multicolumn{8}{|l|}{ Heads } \\
\hline Male & & 69 & 22.0 & 245 & 78.0 & 314 & 89.5 \\
\hline Female & & 17 & 42.5 & 23 & 57.5 & 40 & 10.5 \\
\hline \multicolumn{8}{|l|}{ Marital status } \\
\hline Married & & 71 & 22.4 & 246 & 77.6 & 317 & 89.5 \\
\hline Single & & 8 & 61.5 & 5 & 38.5 & 13 & 3.8 \\
\hline
\end{tabular}




\begin{tabular}{lrrrrrr}
\hline $\begin{array}{l}\text { Divorced } \\
\text { Separated }\end{array}$ & 0 & 0.0 & 5 & 100 & 5 & 1.4 \\
Widow/widower & 5 & 50.0 & 5 & 50.0 & 10 & 2.8 \\
$\begin{array}{l}\text { Education (years } \\
\text { schooling) }\end{array}$ & 2 & 22.2 & 7 & 77.8 & 9 & 2.5 \\
7 years & & & & & & \\
$8-12$ years & & & & & & \\
HH Dependants & 33 & 24.1 & 262 & 75.9 & 345 & 96.9 \\
$1-5$ & 37.5 & 6 & 62.5 & 9 & 3.1 \\
6 and above & & & & & & \\
\hline
\end{tabular}

Note: $\mathrm{n}=$ number of respondents $(\mathrm{HHHs}), \%=$ per cent. Further, Table 2 presents marital status, ages of HHHs, education level and Family size/HH dependents

\subsection{Socio-Demographic Characteristics of Respondents}

The findings in Table 2 show that majority (78.9\%) of non-CHF members were aged between 35 and 59 years, while $66.7 \%$ of non-members and 33.3 percent of CHF members were aged between 60 years and above respectively. This suggests that the majority of HHs were headed by matured people capable of making decisions on whether or not to join the CHF. The results are centrally to UNFPA (2019) who argued that most of the elderly groups are busy with productive jobs hence they do not take care to their dependants. The study by Winzer $e t$ al. (2018) claimed that the age of stable health is at 20 to 50 years old. Girei and Giron (2012) observed that CHF membership tends to increase with the relationship of the age of dependants who are much vulnerable to diseases.

From Table 2, the results show that 22.0 percent were male household members 42.5 percent were female household members, 78.0 percent were male household non-members and 57.5 percent were female household non-members.. Generally, Female Household Heads (FHHHs) and Male Household Heads (MHHHs) recorded 10.5 and 89.5 percent, respectively as compared to the Tanzania national level of proportions, which show that FHHHs and MHHHs are 24.5, and 75.5 percent respectively (World Bank, 2015). Traditionally, males in many HHs in Tanzania are not close to the care of their families for health security. This was confirmed by all FGDs in the study under the discussion of who take liabilities between men and women once family member becomes sick. Females, most of the time, are closer to their families. As reported by UNFPA (2019), women should be empowered by community because in most cases, they are more concerned with taking care of family members than is the case with men. Even when one of the family members gets sick, women are more concerned in providing health services. Studies by Waheke (2015) and Chingonikaya et al. (2018) reported that FHHHs have fewer chances of participating in community organisations because most of HHs is headed by males who take liabilities of participating in those organisations whose membership unit is the household. Women believe that by so doing they may be socially accepted and protect their marriages.

The findings also indicate that, there were few (22.4\%) married CHF members as compared to many $(77.6 \%$ ) non-CHF members (Table 2). This indicates that majority of the community 
members were married as a result; men appeared to be heads of households (HHHs) among married couples. The findings are congruent to the findings in a study by Waheke (2015) in Songea District, in Ruvuma Region, Tanzania. in another study, Narayan (2010) indicated that married couples were most likely to engage in community organs compared to female household heads. This is because married couples have high number of dependants including children aged below 5 years who are at higher risk of contracting diseases as other children.

The findings as indicated in Table 2 show that CHF members who attended seven years of schooling and eight to twelve years of schooling were few accounting to 24.1 and 37.5 percent of the respondents as compared to non-members who were 75.9 and 62.5 percent (Table 2). This implies that almost all HHHs had primary education, and presumably could read and write. The level of education may predict that many respondents had little knowledge on health insurance schemes, specifically the CHF as it has reported by URT (2017) that education plays a key role in building human capability in general as well as developing skills for understanding the environment. A study by Waheke (2015) reported that most of her respondents were primary school leavers and the rest had no formal education. Bahaman et al. (2009) revealed that the majority of the informal sector workers always have lower education.

The results as shown in Table 2 indicated that majority (85\%) of the respondents had a range of 1-10 dependants followed by 15 percent of HHs with 11-15 dependants (Table 2.0). The ratios of $\mathrm{HHs}$ dependants for $\mathrm{CHF}$ members and non-members were 18.8 and 27.4 percent respectively as opposed to compared to CHF non-members who accounted for 81.2 and 72.6 percent respectively (Table 2.0). This implies that the fertility rate was higher in the study area as compared to the average Tanzanian household, which is five persons per HH (URT, 2012). This may discourage HHs from joining CHF, because the fund limits only six members per one card. When the size exceeds 6 members, the HH should have another card as the condition suggests. Yet, the majority of HHs in the study area were low-income earners, as reported by Narayan (2010) who indicated that married couples are most likely to engage in social schemes compared to single HHs. This is because married HHs had high number of dependants; hence, they are at a higher risk of getting sick members compared to single ones.

\subsection{Enrolment of Community to CHF in the Study Area}

Table 3. Households' monthly income and saved income due to use of CHF

\begin{tabular}{lccc}
\hline Variable & Minimum & Maximum & Mean \\
\hline Monthly income (TZS) & 10000 & 260000 & 76988.70 \\
Saved amount (TZS) & 15000 & 100000 & 52848.84 \\
\hline
\end{tabular}

The results from this study revealed that CHF members in the study area were only 86 households (HHs) which accounted for $24.3 \%$, with $268 \mathrm{HHs}$ which is 75.7 percent being non-members. The reasons that were given by KIIs and FGDs for low membership to CHF in the study area include lack of money to pay for registration and lack of awareness about CHF existence. Similarly Ware (2013) and URT (2001) report that the reasons for low coverage of 


\section{$\triangle$ Macrothink}

Journal of Public Administration and Governance ISSN 2161-7104

$\mathrm{CHF}$ were lack of money for contributions and lack of awareness of CHF existence. This observation was supported by one of FGD participant at Mbuza village who his argument agreed with all participant, she said that:

“... CHF officials are not conducting seminars and meetings on CHF matters that is why we are not well informed about it, in most cases we are advised by Clinical Officers at Dispensary to join CHF when we are sick..." (FGD participant, Mbuza village, $14^{\text {th }}$ December 2018).

\subsection{Households' Monthly Income and Saved Income Due to Use of CHF}

Table 4.0. Distance from HH to Health facility (in $\mathrm{km})(\mathrm{n}=354)$

\begin{tabular}{|c|c|c|c|c|c|c|}
\hline \multirow[t]{2}{*}{ Variable } & \multicolumn{2}{|c|}{ CHF Member } & \multicolumn{2}{|c|}{ CHF Non-Member } & \multicolumn{2}{|r|}{ Total } \\
\hline & $\mathbf{n}$ & $\%$ & $\mathbf{n}$ & $\%$ & $\mathbf{n}$ & $\%$ \\
\hline \multicolumn{7}{|c|}{ Distance from $\mathrm{HH}$ to } \\
\hline \multicolumn{7}{|c|}{ Health facility $(\mathbf{K m})$} \\
\hline $0-1 \mathrm{Km}$ & 85 & 24.3 & 265 & 75.7 & 350 & 98.9 \\
\hline 1.1 $\mathrm{Km}$ and above & 1 & 25 & 3 & 75 & 4 & 1.1 \\
\hline
\end{tabular}

Note: $\quad \mathrm{n}=$ number of respondents $(\mathrm{HHHs}), \%=$ per cent. Further, Table 4 presents distance from $\mathrm{HH}$ to Health facility (in $\mathrm{KM}$ )

The mean saved monthly income per HHs as indicated in Table 3, was 76988.70 with minimum of 10000 and a maximum of 260000 . This implies that majority of HHs in the study area are low-income earners as their income is around 76 988.70 TZS, as opposed to the national monthly per capita income of 204 874.75 TZS in 2018 (The Citizen Newspaper of $13^{\text {th }}$ June 2019). This indicates that most of the HHs are health unsecured, as they were not CHF members. The CHF members access health care services at very low prices by contributing only 10000 TZS per annum for a Membership card which covers six household members. On the other hand, non-members were not financially well which could secure them from health related problems. The saved amount due to CHF use was the other component of seeking for health security (Table 3.0). The mean amount saved was 52848.84 with a minimum of 15000 and a maximum of 100 000. This implies that apart from low health services provided by CHF to its members, members save money that would have been spent for health services to be spent in other expenditures. This can lead into an improved social-economic status of CHF members, hence an improved human capital that can provide more labour in other sectors such as crop productions, petty businesses and other informal activities. Furthermore, children would increase attendance and performance in schools due to improved health conditions and decreased morbidity and mortality rate.

\subsection{Distance From HH to Health Facility (in Km)}

Distance from HHs to the health facilities was one of the challenges for CHF membership in this study (Table 4.0). The findings revealed that 99.1 percent of the respondents were close 
to health facilities, as the distances were not exceeding one kilometre, while only 0.9 percent was living more than one kilometre from the health facilities. This indicates that distance was not a strong reason for the HHs failure to join the $\mathrm{CHF}$, because each village in the study area had a dispensary, which was found in a central part of each village where it was easily accessible. As revealed by Macha et al. (2015), most of the HHs that were more than a km from the health facilities was not CHF members due to long distance.

\subsection{Facilities at Dispensary}

Table 5.0. Challenges in accessing health services

\begin{tabular}{|c|c|c|c|c|c|c|}
\hline \multirow[t]{2}{*}{ Variable } & \multicolumn{2}{|c|}{ CHF Member } & \multirow{2}{*}{\multicolumn{2}{|c|}{$\begin{array}{r}\text { CHF } \\
\text { Non-Member }\end{array}$}} & & Total \\
\hline & n & $\%$ & n & & n & $\%$ \\
\hline $\begin{array}{l}\text { Lack of medicine in the health } \\
\text { facilities }\end{array}$ & 53 & 37.1 & 90 & 62.9 & 143 & 39.4 \\
\hline Poor laboratory services & 22 & 23.9 & 70 & 76.1 & 92 & 29.0 \\
\hline $\begin{array}{l}\text { Too costly health services by direct } \\
\text { payments }\end{array}$ & 0 & 0.0 & 62 & 100 & 62 & 16.5 \\
\hline Lack of money for contribution & 0 & 0.0 & 31 & 100 & 31 & 8.1 \\
\hline No challenges & 11 & 42.3 & 15 & 57.7 & 26 & 7.0 \\
\hline
\end{tabular}

Note: $\mathrm{n}=$ number of respondents $(\mathrm{HHHs}), \%=$ per cent. Further, Table 5 presents the challenges faced in accessing health services.

The respondents were required to mention challenges they faced in using CHF health services. A good proportion (39.4\%) of the respondents cited lack of drugs in the health facilities, and this was reported by 37.1 percent of CHF members and 62.9 percent of non-members as indicated in Table 6. One of the key informants from Mbuza village in Mkowe Ward had this to say:

“... Most of the requested medicines for from the Medical Store Department (MSD) are not supplied. It is a challenge that is out of our control..." (A key informant from Mbuza village on $14^{\text {th }}$ December 2018).

Lack of laboratories in dispensaries was mentioned as one of the challenges against the provision of good health services to $\mathrm{CHF}$ members Table 5 indicates that, about 23.9 percent of CHF members and 76.1 percent of non-members cited this factor. Lack of laboratory is partly caused by the health policy, which states that it is not necessary for dispensary to have laboratory because they attend mainly primary diseases, which are simple to be observed by physician without using laboratory facilities (URT, 2003).

The other challenge reported as a barrier against CHF membership was contribution rate. About 26.3 percent of HHs complained that the fee charged by the CHF scheme was high as compared to their income as shown in Table 3. Majority of the people could not afford to pay 10000 TZS per year because they are low-income earners as their monthly income was 
below 100000 TZS (Table 3) as compared to 179 437.50 TZS the National average per capita income (URT 2013). This means they could not afford even direct payments. This is in line with the findings by Kamuzora et al. (2007) who reported that inability to pay for annual contribution is a barrier for the poor HHs against joining CHF. On the other hand, CHF policy requires CHF officials from the District Council to consult local people of a particular district before setting contribution rates (URT 2003), which should be affordable and agreed by people in the area. This was not considered as it was evidenced by all FGD's participants that the criterion was not observed. The other challenge was poor health services about which 26.0 percent of the respondents complained. This was reported during FGDs at Kasote and Kasanga Villages that, poor health services that include lack of medicines and laboratory services discouraged people from joining the Scheme, while 7.3 percent reported to have not experienced any challenge.

\subsection{Contributions of Community Health Fund to Social Health Security}

Table 6.0. The contributions of CHF to members' health security

\begin{tabular}{lccccccc}
\hline Variable & B & $\begin{array}{c}\text { Std. } \\
\text { Error }\end{array}$ & Beta & t-value & $\begin{array}{c}\text { Sig. } \\
\text { (P-value) }\end{array}$ & Tolerance & VIF \\
\hline $\begin{array}{l}\text { Community awareness on } \\
\text { CHF }\end{array}$ & 0.251 & 0.094 & 0.162 & 2.67 & 0.008 & 0.739 & 1.353 \\
CHF membership & -0.001 & 0.113 & -0.001 & -0.011 & 0.991 & 0.594 & 1.685 \\
Training on CHF matters & 0.044 & 0.125 & 0.022 & 0.349 & 0.727 & 0.658 & 1.52 \\
CHF Supplies of & -0.138 & 0.056 & -0.163 & -2.47 & 0.014 & 0.629 & 1.59 \\
$\begin{array}{l}\text { medicine to its members } \\
\text { Lack of choices for health }\end{array}$ & 0.061 & 0.052 & 0.073 & 1.166 & 0.244 & 0.705 & 1.418 \\
$\begin{array}{l}\text { services to CHF members } \\
\begin{array}{l}\text { Accessibility of health } \\
\text { services to CHF members }\end{array}\end{array}$ & 0.036 & 0.062 & 0.042 & 0.584 & 0.56 & 0.525 & 1.906 \\
\hline
\end{tabular}

Dependent Variable: Frequencies of $\mathrm{HH}$ members to go to Hospital from January to December in 2018. $\mathrm{SS}=10.474, \mathrm{df}=7, \mathrm{MS}=1.496, \mathrm{~F}=3.048, \mathrm{P}<0.05, \mathrm{R} 2=24.4$

From the linear regression model the analysis showed that community awareness on CHF and CHF supplies of medicines to its members were significant on the contributions of CHF to its members health security ( $<<0.05 ; \mathrm{R}^{2}=24.4 \%$ ) (Table 6). The regression results also showed multicollinearity by examining tolerance and the Variance Inflation Factor (VIF). The results indicated that the independent variables involved in the model have no any influence on each other as their values were above the recommended 0.1 and below 5 for tolerance and VIF values respectively (Stine, 1995). This indicates that frequencies of HH members of going to hospital had a strong linear relationship with the selected variables. CHF membership and supplies of medicine from $\mathrm{CHF}$ to its members showed a negative correlation with frequencies of $\mathrm{HH}$ members of going to hospital, while the rest of the independent variables had positive correlation with the dependent variable. Community awareness on $\mathrm{CHF}$ existence had significant ( $\mathrm{p}<0.05$ ) positive relationship with frequencies of $\mathrm{HH}$ members of going to hospital. However, CHF supplies of medicine to its members showed a significant ( $p$ 
$<0.05)$ negative relationship with frequencies of $\mathrm{HH}$ members going to hospital. It is a known fact that linear, negative $\beta$ coefficient of independent variables affects negatively the dependent variable, but positive $\beta$ coefficients most often affect dependent variable positively (Stine, 1995).

\section{Conclusion and Recommendations}

The study concludes that, there were contributions of Community Health Fund to social health security among members in the study area. This includes assurance of the provision of better health services when they get sick, an increase of social-economic well-being, and increased number of school going children, good performance in schools, and reduction of morbidity and mortality rate, disabilities, and deaths. The main challenges revealed by this study include lack of community awareness on the existence of CHF, which resulted to low rate of CHF membership. Lack of medicine in the Dispensaries together with poor health services were the barrier for people against joining the scheme. The study concludes that, majority of people who were aware of CHF did join the fund due to financial hardship. Nevertheless, such respondents suggested that if given the opportunity they were able to contribute valuable commodities such as maize, beans and other crops with the same value of contribution rate (fee), in lieu of hard cash so that they could qualify for CHF membership.

Thus, the study recommends that, CHF officials should conduct enough sensitization seminars and meetings to the community members of the existence of CHF to enable members join the Scheme. On the other hand, they should consider enrolments of CHF members to the scheme as a permanent agenda in their meetings to encourage more households become members of CHF.

It also recommends that MSD should supply enough medicine to the Dispensaries according to their needs; this should be in line with improvements of health services provision. The government through Ministry of Health, Gender, Community Development, Elderly and Children (MHGCDEC) and Local Government Authority should take the responsibility of funding community-based health insurance so that its membership should be compulsory to all communities. Otherwise, $\mathrm{CHF}$ officials have to consider accepting valuable commodities to be used as substitute for cash payments for CHF membership contributions

\section{Acknowledgements}

Our sincere thanks go to Sokoine University of Agriculture for granting research permission to undertake this study. We extend our acknowledgements to Kalambo District Council Officials who were involved in this study, including the District Commissioner (DC), District Executive Director (DED), and District Medical Officer (DMO). In addition, we acknowledge the goodwill of Ward Executive Officers, Village Executive Officers, and Clinical Officers in the study area. Finally, we give many thanks to CHF members and non-members who participated in FGDs as well as household heads that were ready for a questionnaire based survey. 


\section{References}

Bahaman, A. S., Hayrol, M. S., Azril, M. H., Salleh A. H., \& Narimah, I. (2009). ICT contribution in increasing agro-based entrepreneurs 'productivity in Malaysia. Agriculture Extension and Social Sciences, 5(3), 93-98.

Byers, B. A. (1996). Understanding and influencing behaviors in conservation and natural resources management. [www.coloradomtn.edu] site visited on 10/05/2018.

Carapinha, J. L., Ross-Degnan, D., Dester, A. T., \& Wagner, A. K. (2010). Health insurance system in five sub Saharan African countries. In: Medicine Benefits and Data for Decision Making. Article in Press. 10pp.

Chingonikaya, E. E., \& Salehe, F. S. (2018). Attitudes of community towards female genital multilation in Manyoni District, Singida Region Tanzania. Journal of Education, Society and Behavioural Science, 25(1), 1-11. https://doi.org/10.9734/JESBS/2018/40740

Girei, A. A., \& Giroh, Y. D. (2012). Analysis of the factors affecting sugarcane (saccharum officinarum) production under the out-growers scheme in Numan Local Government Area Adamawa State, Nigeria. Advances in Agriculture, Sciences and Engineering Research Journal, 2(5), 1158-1164.

HPSS. (2018). Health promotion and system strengthening. [https://www.eda.admin.ch/ dam/countries/countries-content/Tanzania/en/HPSS_Factsheet_EN.pdf] site visited on $13 / 04 / 2018$.

ILO. (2018) International labour standards on social security. [https://www.ilo.org/global/ standards/subjects-covered-by-international-labour-standards/social-security/lang--en/index.h tm] site visited on 26/9/2018.

Kivelege, G. (2015). Community Health Fund and quality health services in Morogoro District Tanzania. Dissertation for Award Degree of Master of Arts in Rural Development at Sokoine University of Agriculture, Morogoro, Tanzania, 67pp.

Macha, J., Harris, B., \& Garshong, B. (2015). Factors influencing the burden of health care financing and the distribution of health care benefits in Ghana, Tanzania and South Africa. Health Policy and Planning, 27(1), 154. https://doi.org/10.1093/heapol/czs024

Macha, J., Kuwawenaruwa, A., Makawia, S., Mtei, G., \& Borghi, J. (2015). Determinants of community health fund membership in Tanzania: a mixed methods analysis. [https://www.ncbi.nlm.nih.gov/pmc/articles/PMC4246628] site visited 20/5/2018.

Martin, G. (2017). The leading 16 countries with better health care system in the world. [www.un.org > africarenewal > magazine] site visited 19/5/2018.

Marwa, B., Njau, B., Kessy, J., \& Mushi, D. (2013). Feasibility of Introducing Compulsory Community Health Fund in Low Resource Countries: Views from the Communities in Liwale District. 298pp. https://doi.org/10.1186/1472-6963-13-298

Msuya, J. M., Jütting, J. P., \& Asfaw, A. (2004). Impacts of Community Health Insurance 
Schemes on Healthcare Provision in Rural Tanzania: Membership in Tanzanian Community Health Funds Drastically Improving Access to Healthcare. ZEF Development Policy. Bonn. 82pp.

Mtei, G., \& Mulligan, J. (2007). Community Health Funds in Tanzania: A Literature Review. Ifakara Health Research and Development Centre, Morogoro, Tanzania. 15pp.

Mubyazi, G. M. (2004). The Tanzania policy on health care fee waivers and exemption in practice as compared with other developing countries: Evidence from recent local studies and international literature. East African Journal of Public Health, 1(1), 1-10.

Narayan, S. (2010). Contract farming as frictional equilibrium: A theoretical viewpoint with empirical evidence form Southern India. Sustainable Development, 9(2), 2016-244.

Rogers, R. W. (1983). Cognitive and physiological processes in fear appeals and attitude change: A revised theory of protection motivation. In: Social Psychophysiology. (Edited by Cacioppo, J. and Petty, R.), Guilford Press, New York. pp. 153 - 177.

Temba, M. F., \& Leonard, W. (2013). Social security right in Tanzania: An overview of the forms, scope and the way forward. Journal of Policy and Leadership, 2(1), 136-152 .

Trading Economics. (2018). Tanzania GDP per capita. [https://tradingeconomics.com/ Tanzania/gdp-per-capita] site visited on 06/12/2019.

UNFPA (2019). United Nations Population Fund: women empowerment. [https://www. unfpa.org/resources/issue-7-womenwerment-empo] site visited on 20/6/2019.

URT (2001). Community Health Fund Act. Dar es Salaam.

URT (2003). National Health Policy. Ministry of Health, Dar es Salaam, Tanzania. 32pp.

URT (2008). Report on Medicines Coverage and Health Insurance Programs Survey in Tanzania. Ministry of Health and Social Services, Dar es Salaam, Tanzania. 33pp.

URT (2012). National Bureau of Statistics, Dar es Salaam Tanzania. 244pp.

URT (2012). Rukwa Region Investment Profile. Prime Minister Office, Dar es Salaam, Tanzania, 48pp.

URT (2015). Annual Health Sector Performance Profile 2014/2015. Dar es Salaam Tanzania. $128 \mathrm{pp}$.

URT (2016). Annual Health sector performance profile 2014-15.

URT (2017). Tanzania Development Report. Social policy in the context of economic transformation.

URT (2019). Tanzania's budget speech citizen. The Citizen Newspaper of Tanzania [www.thecitizen.co.tz >News] site visited 20/06/2019.

URT (2003). National Health Policy. Ministry of Health Dar es Salaam Tanzania. 32pp. 


\section{Macrothink}

Journal of Public Administration and Governance ISSN 2161-7104 2020, Vol. 10, No. 3

Waheke, J. W. (2015). Effects and challenges of community health fund on accessibility to health care services: A case of Songea District, Tanzania. Dissertation for Award MSc Degree at Mzumbe University, Morogoro, Tanzania, 69pp.

WHO (2003). Community Based Health Insurance Schemes in Developing Countries: Facts, Problems, and Perspectives. Discussion Paper No. 1. World Health Organization, Geneva. 39pp.

WHO (2007). A safer future: global public health security in the $21^{\text {st }}$ Century. [https://www.who.int/health-security/:] site visited on 15/07/2019.

WHO (2015). World Health Statistics. Dar es Salaam, Tanzania. 86pp.

Winzer, R., Kimmo, S., \& Lene, A. (2018). What predicts stable mental health in the 18-29 age group compared to older age groups? Results from the Stockholm Public Health Cohort 2002-2014. https://doi.org/10.3390/ijerph15122859

World Bank (2015). Collection of development indicators. [blogs.worldbank.org> opendata> release-world-development-indicators] site visited on 12/02/2020.

\section{Copyright Disclaimer}

Copyright for this article is retained by the author(s), with first publication rights granted to the journal.

This is an open-access article distributed under the terms and conditions of the Creative Commons Attribution license (http://creativecommons.org/licenses/by/4.0/). 